\title{
Analysis of the Characteristics of EIA Review System in Taiwan, A Case Study of Pinnan Industrial Park
}

\author{
Binghua Li (Corresponding author) \\ Department of Environment Science and Technology, Tokyo Institute of Technology \\ G5-9 4259 Nagatsuta, Midori-word, Yokohama 226-0852, Japan \\ Tel: 81-45-924-5550Ｅ-mail: bhua168@gmail.com
}

Jing Du

Key Laboratory of Industrial Ecology and Environmental Engineering, MOE.

Dalian University of Technology

No.2 Linggong Street Ganjingzi District, Dalian 116024, China

Tel: 86-411-8470-6172Ｅ-mail: dujingdl@mail.dlut.edu.cn

Sachihiko Harashina

Department of Environment Science and Technology, Tokyo Institute of Technology

G5-9 4259 Nagatsuta, Midori-word, Yokohama 226-0852, Japan

Tel: 81-45-924-5550Ｅ-mail: sahara@depe.titech.ac.jp

\section{Shigeo Nishikizawa}

Department of Environment Science and Technology, Tokyo Institute of Technology

G5-12 4259 Nagatsuta, Midori-word, Yokohama 226-0852, Japan

Tel: 81-45-924-5540 E-mail: nishikizawa.s.ab@m.titech.ac.jp

Kuang-huei Huang

Department of Environmental Resources Management, Chia Nan University of Pharmacy \& Science

E-mail: khhuang@gmail.com

Received: December 5, $2011 \quad$ Accepted: January 4, $2012 \quad$ Published: February 1, 2012

doi:10.5539/jsd.v5n2p54 URL: http://dx.doi.org/10.5539/jsd.v5n2p54

\begin{abstract}
Environmental impact assessment is widely recognized as an effective tool for supporting the sustainable development and accepted as an important decision support tool in planning. Although more than 100 countries have set up their environmental impact assessment systems, less than half are predicated on clear and specific legal provisions. The review system that is used within Taiwan is different from other countries in the manner in which the application is processed and reviewed. Thus, the current paper attempts to analyze the process and characteristics of EIA review system in Taiwan, thereafter, Pinnan industrial park project EIA is used as an example to demonstrate the detailed EIA review system.
\end{abstract}

Keywords: Environmental impact assessment, Review system, Taiwan, Pinnan industrial park, Characteristic analysis

\section{Introduction}

Environmental impact assessment (EIA) was originally made legislation in the US in the National Environmental Policy Act (NEPA) 1969. As it takes into consideration the costs and benefits both of maintaining 
environmental ecosystems and of building development projects, and of their effect on the quality of the environment, it has since evolved as it has been used increasingly in many countries around the world (Beattie, 1995; Sadler \& Verheem, 1996; Lawrence, 1997; Connelly \& Smith, 1999; Nobel, 2000; Partidario, 2000; Kapoor, 2001; Burdge, 2003; Roudgarmi et al., 2008; Du et al., 2010). The International Association for Impact Assessment (IAIA) defines an environmental impact assessment as "the process of identifying, predicting, evaluating and mitigating the biophysical, social, and other relevant effects of development proposals prior to major decisions being taken and commitments made" (IAIA, 1999). EIA, therefore, represents a proactive, preventative approach to environmental management and protection (Lawrence, 2000).

Several international agencies have also involved themselves with EIA. The Organization for Economic Cooperation and Development (OECD) recommended that member governments adopt EIA procedures and methods. In 1989 the World Bank ruled that EIA for major projects should normally be undertaken by the borrower country under the Bank's supervision. The United Nations Environment Programme (UNEP) also made recommendations to member states regarding the establishment of EIA procedures and established goals and principles for EIA. It subsequently issued guidance on EIA in developing countries. Just as there are huge differences in EIA systems in the developed world, so there are between EIA systems in developing countries.

Taiwan has been conducting EIA in conjunction with its major development projects in a rapidly growing population and economy driven by commercial and industrial endeavor situation. Originally, most environmental legislation and regulations were drafted by the Department of Health (DH). With little involvement by any powerful clientele groups, regulations proposed by $\mathrm{DH}$ could be easily overruled by other government units (Tang et al., 2005). For example, the first EIA law draft proposed by DH in 1983 bowed to economic bureaucrats' opposition, and the legislative effort was delayed (Ho, 2004). Nevertheless, Taiwan confirmed its commitment to EIA ideals in 1985 when the Executive Yuan approved the "Project to Strengthen and Promote Environmental Impact Assessment". Two years later, the Environmental Protection Bureau within DH was elevated to a ministry-level agency, the Environmental Protection Administration (EPA). EIA in Taiwan underwent fundamental transformations in 1994 when the formal EIA Act was codified by Executive Yuan (Huang, 2003). And then a series of regulations (sub-rules) were promulgated which were hierarchically arranged in tiers, such as, Environmental Impact Assessment Enforcement Rules in 1995, EIA items and Screening Criteria for Development Activities in 1995, Working Guidelines for the EIA Act for Development Activities in 1997, EIA Regulation for Government Policy in 2000, EIA Regulation for Military Secrets or Emergency in 2002 etc. (Tang \& Tang, 1997; Chen, 2009).

Although many countries have followed in adopting EIA systems to suit their regional needs since the inception of the EIA in NEPA (1969), yet there are still differences between the legislative elements and review system these various countries used ( $\mathrm{Li} \&$ Harashina, 2007). Thus, this current paper attempts to examine the process and characteristics of EIA review system in Taiwan, and then a case study for demonstrating the detailed review system of Pinnan industrial park EIA in Taiwan is introduced.

\section{EIA Review Process in Taiwan}

In Taiwan, development projects for which there is concern of adverse impact on the environment should prepare an environmental impact statement (EIS) for the phase- I EIA, and then competent authority transfer the EIS to the responsible agency for EIA for review. Phase- I EIA is simplified to expedite the evaluation and review to establish the extent of any potential adverse impact on the environment. The developer should edit an environmental impact assessment report (EIAR) for the phase- IIEIA for those circumstances in which the review result of the EIS is concerned with a significant impact on the environment. The review results of EISs of EIARs can be classified into three categories: conditional approval, phase- II EIA, or disapproval on the development project (Chi, 1994). The EIA review process is described in Figure 1.

The fundamental purpose of the screening procedure is to decide on whether an EIS should be issued, and the scoping procedure is essentially used to specify what environmental factors should be subsumed into the EIAR. The scoping process is used in conjunction with the screening process, as preliminary discriminators for any proposal that is put forward for consideration. In Taiwan, there is a legal process which must be followed, by the Responsible Agency, to establish the guideline for the scope of the EIA study. It should be noted that although the scoping could be considered part of the screening process, it is usually applied after the development planner is required to submit an EIAR for review and approval in Taiwan.

\section{Characteristics of EIA Review System in Taiwan}

Under the current EIA system the most important process that must be undertaken it to determine, and specify if the policy, or development should be categorized as being either significant or crucial. The EIA Act requires that 
the assessing unit issues the EIS/EIAR in the planning phase to provide for the establishment of a suitable review procedure, which can be divided into a number of segments as follows.

The review system that is used within Taiwan is different from other countries in the manner in which the application is processed and evaluated (reviewed). The processing phase is generally know as procedure review and the initial project evaluation is know as the preliminary review which may include a combined review, or associate review that examines the impact on land and soil conservation, and will progress to the public meeting review as the final stage. These several stages have a tendency to elongate the review process, however, in the interests of all parties, and ensuring that procedural fairness is adopted, it is considered a necessity to undertake the exhaustive process.

\subsection{Procedure Review}

Once the Responsible Agency for EIA receives the EIS and commences reviewing the data (including any modifications or corrections) the procedure review is considered to have commenced. Since 1997, the Taiwan EPA have been required, by the EIA Act, to abide by the 'Working Guidelines for the EIA Act for Development Activities' which requires the Responsible Agency to ensure correct documentation is provided on the submission of any EIS or EIAR submitted by the project proponent. Essentially, it provided an opportunity for the Responsible Agency for EIA to notify any applicant of any deficiencies that may be evident within their proposal, before the due date, thereby allowing them the opportunity to amend, modify, or withdraw the application.

After the EIA document has passed the procedure review process, it will then enter the solid and final review stage. This review includes a number of steps: preliminary review, initial review and committee meeting review (final review), which will be examined in the following sections.

\subsection{Preliminary and Initial Review}

The project proponent can submit the draft, with relevant information and data, while he makes the EIS. The competent authority transfers it to the responsible agency for EIA for preliminary review. The responsible agency for EIA can invite the committee members of the EIA review committee, relevant scholars, experts, authorities and communities to hold the preliminary review meeting. They will then inform the project proponent of the conclusions regarding the key point of EIA operation.

Under following circumstances: strong influence on other property, large scale development, and high environmental sensitivity, an initial review is required. The review committee should be comprised of professional members from the EIA review committee, and others who are considered to be regional experts. Other than exceptional cases, which may need to make a survey before consideration, most of these reviews consist of a meeting which allows the developer to present the relevant information to committee.

\subsection{Final Review}

The development application will pass through the above review processes after which a decision as to whether it needs to be put before the committee members and experts of EIA review committee, or alternatively be sent to the final meeting of EIA review committee. According the EIA Act, the application needs to undertake a final review by committees which represent each tier of Responsible Agency for EIA, called associating review meeting or final review meeting.

Resulting from this, the project proponent must comply with the review comments to make proper modification to its EIA document before being submitted for final approval. This document is the required to be displayed, in form, including the review committee conclusions, in prescribed public place near the development site and published in the press and governmental bulletins.

\section{Case Study}

\subsection{Case Description}

Since 1994, many projects, such as the Pinnan industrial park (1994), the Hwenhwen dam (1996), the Kuanhsi industrial zone (1996), a Bayer chemical plant (1996), and the Haitu power plant (1997), were highly publicized for their EIA processes. In this paper, EIA review process of Pinnan industrial park in Taiwan is demonstrated as the case study.

The project was originally jointly proposed in 1994 by the two industrial giants Yieh Loong Enterprises and the Tuntex Company. Yieh Loong planned to invest NT\$112 billion (US\$3.25 million at that time) to construct a large steel mill capable of turning out 7.5 million metric tons annually, with the output targeted to replace materials that are now imported. Tuntex wanted to build Taiwan's seventh naphtha cracker, a NT\$271 billion 
(US\$7.86 million at that time) petrochemical complex, which can process 300,000 barrels of crude oil daily. Combined with the sixth naphtha cracker, the proposed facility would boost the island's self-supply ratio of ethylene to 100 percent, up from just 43 percent. The planned industrial park chose its location near the estuary of the Tsengwen River to build an industrial harbor on the southeastern coast of Taiwan (Figure 2). This project was certainly the largest case under EIA review at that time.

\subsection{Review Process of Pinnan Industrial Park EIA}

During the review period (1995-1999), the opposition sought to delay final passage. This strategy of postponement worked during the first stage of the EIA. At that time, Tunex and Yieh Loong enjoyed backing from local politicians and were eager to see the project approved. Prior to the EIA completion, the Ministry of Economic Affairs (MOEA) had already stated its unconditional support for the Pinnan project, and in June 1996, the MOEA even vowed to begin the construction process within half a year. In order to counter this, the opposition successfully persuaded and lobbied reviewers to accept the idea of a second stage for the review process in 1996. The second stage of the EIA began in early 1998. Participants in the review process included 43 committee members, scholars and experts, 42 related institutions and agencies, 39 concerned groups, and 2 legislators. The committee identified a set of technical issues for review, including site alternatives, harbor alternatives, coastal erosion, lagoon protection, water supply and drainage, impact on the Tainan Science-based Industrial Park, $\mathrm{CO} 2$ emission and pollution control, acid rain and what measures were essential to preserve the black-faced spoonbill, the ecosystem and local fisheries. Final conclusions were reached by the committee only after holding 17 specific-task group meetings from April 1998 to December 1999. The detailed review process of Pinnan industrial park EIA was shown in Figure 3.

The convinced EIA committee kept demanding that the developers presented more updated data during reviewing process. Pinnan industrial park planned to be 3733 ha, of which 2367 ha had been set aside for the chemical and steel plants and 1406 ha for an industrial harbor. According to EPA's mandate, only 1016 ha could be available for the two plants, meaning that they should have to be scaled down. In certain points, the review committee succeeded in downsizing the scale of development, therefore reducing the ecological impact. The conservation groups did their best to promote the value of this coastal marsh. Now the area has become a famous site for eco-tourism, bird watching, and oyster dinning. As a consequence, the lagoon development ratio was reduced from its original $100 \%$ usage to no more than $5 \%$ along with other reducing items. The reducing items of Pinnan industrial park project are concluded in Table 1. The Pinnan project was ultimately granted final approval with the adoption of a number of provisos, twenty-seven conditions, and eight supplements. The rearranged site which was changed from original one for $9 \mathrm{~km}$ towards north could be seen in Figure 4.

Clearly, the environmentalists had won a major victory by inserting their concerns into the EIA review agenda. With the addition of these items, the Pinnan project underwent the strictest EIA review ever in Taiwan. Compared with its four-year EIA review process, previous cases of similar in scale required no more than four months. As seen in the Pinnan case, EIA review process had the effect of redirecting environmental protests in Taiwan.

\section{Conclusion}

Comparing with existing international systems, it is apparent that the EIA system which has evolved in Taiwan has its own focus and individual characteristics. The review process requires and encourages civic participation and public consultation at early stages of the EIA process and it has progressed to become an open review and a more democratic forum, with meaningful participation from local residents and public interest groups. Political intervention, of course, is minimized, lest the power distorts the goal of communication without restraint. In the case of the Pinnan project for example, the EPA is not the designated agency in charge of national land planning, determination of protected areas for the black-faced spoonbills, formulation of industrial policy, or the distribution and conversion of water resources. However, EIAs are designed to play an important role in preventing or mitigating environmental impacts. EIA review authority has significant behavior in lessening the controversy between the environment and development, without totally compromising one or the other. In looking at the conclusions laid out in the Pinnan project EIA, the effect to achieve this balance should be foremost apparent.

\section{References}

Beattie, R. B. (1995). Everything you already know about EIA (but don't often admit). Environmental Impact Assessment Review, 15 (2), 109-114. http://dx.doi.org/10.1016/0195-9255(95)00001-U

Burdge, R. (2003). The practice of social impact assessment background. Impact Assessment and Project 
Appraisal, 21 (2), 84-88. http://dx.doi.org/10.3152/147154603781766356

Chen, C. C. (2009). Environmental impact assessment framework by integrating scientific analysis and subject perception. International Journal of Environmental Science and Technology, 6 (4), 605-618.

Chi, C. C. (1994). Growth with Pollution: Unsustainable Development in Taiwan and its Consequence. Studies in Comparative International Development, 29, 23-47. http://dx.doi.org/10.1007/BF02827365

Connelly, J., \& Smith, G. (1999). Politics and the environment: from theory to practice. New York: Routledge.

Jing Du, Fenglin Yang, Ling Xu, Sachihiko Harashina, Binghua Li. (2010). Characteristics of Public Participation in EA: the Potential to Improve Sustainable Environmental Management in China. Journal of Sustainable Development, 3 (2), 187-193.

Ho, M. S. (2004). Contested Governance Between Politics and Professionalism in Taiwan. Journal of Contemporary Asia, 34 (2), 238-253. http://dx.doi.org/10.1080/00472330480000071

Huang, G. H. (2003). Comprehensive Environmental Monitoring and Follow-up No.6 Naphtha Cracking Project in Taiwan. $23^{\text {rd }}$ Annual Meeting of IAIA in Marrakech, Morocco, 2003/6/17-20.

IAIA. (1999). Principle of Environmental Impact Assessment Best Practice. International Association for Impact Assessment.

Kapoor, I. (2001). Towards Participatory Environmental Management. Journal of Environmental Management, 63, 269-279. http://dx.doi.org/10.1006/jema.2001.0478

Lawrence, D. P. (1997). Integrating sustainability and environmental impact assessment. Environmental Management, 21 (1), 23-42. http://dx.doi.org/10.1007/s002679900003

Lawrence, D. P. (2000). Impact significance determination-Back to basics. Environmental Impact Assessment Review, 27 (8), 755-769. http://dx.doi.org/10.1016/j.eiar.2007.02.011

Li, B. H., \& Harashina, S. (2007). An International Comparative Study of Environmental Impact Assessment Systems in Japan and Taiwan. Planning Administration, 30 (2), 49-60.

Nobel, B. F. (2000). Strategic environmental assessment: What is it and what makes it strategic? Journal of Environmental Assessment and Policy Management, 2 (2), 203-224. http://dx.doi.org/10.1016/S1464-3332(00)00014-X

Partidario, M. R. (2000). Elements of an SEA framework improving the added-value of SEA. Environmental Impact Assessment Review, 20 (6), 647-663. http://dx.doi.org/10.1016/S0195-9255(00)00069-X

Roudgarmi, P. et al. (2008). Alternatives evaluation in EIA by spatial multi-criteria evaluation technique. Journal of Food Agriculture Environment, 6 (1), 199-205.

Sadler, B., \& Verheem, R. (1996). Strategic environmental assessment: status, challenges and future directions. Ministry of Housing, Spatial Planning and the Environment of the Netherland. Netherland: the Hague.

Tang, S. Y., \& Tang. C. P. (1997). Democratization and Environmental Politics in Taiwan. Asian Survey, 37 (3), 281-294. http://dx.doi.org/10.1525/as.1997.37.3.01p0232n

Tang, S. Y., Tang, C. P., \& Lo, C. W. (2005). Public participation and Environmental Impact Assessment in Mainland China and Taiwan: Political Foundations of Environmental Management. The Journal of Development Studies, 41 (1), 1-32. http://dx.doi.org/10.1080/00220380420000276554 
Table 1. The items comparison of Pinnan industrial park project (before and after EIA process)

\begin{tabular}{|c|c|c|c|}
\hline Items & $\begin{array}{c}\text { Original proposal } \\
\text { (before EIA) } \\
1995.6 .27\end{array}$ & $\begin{array}{c}\text { Second application } \\
1996.05 .06\end{array}$ & $\begin{array}{c}\text { Proposal modification } \\
\text { (after EIA) } \\
\text { Detailed assess } \\
2006.1 .19\end{array}$ \\
\hline Scale (Ha) & 3,733 & 2,660 & 1,732 \\
\hline The lagoon development ratio (\%) & $\begin{array}{c}100 \\
\text { (about } 1,114 \mathrm{Ha})\end{array}$ & 29.6 & 4.982 \\
\hline Scale for industrial harbor (Ha) & 1,406 & 1,738 & 1,123 \\
\hline Scale for chemical and steel plants \\
(Ha)
\end{tabular}

Adapted from: Pinnan project EIS \& EIAR

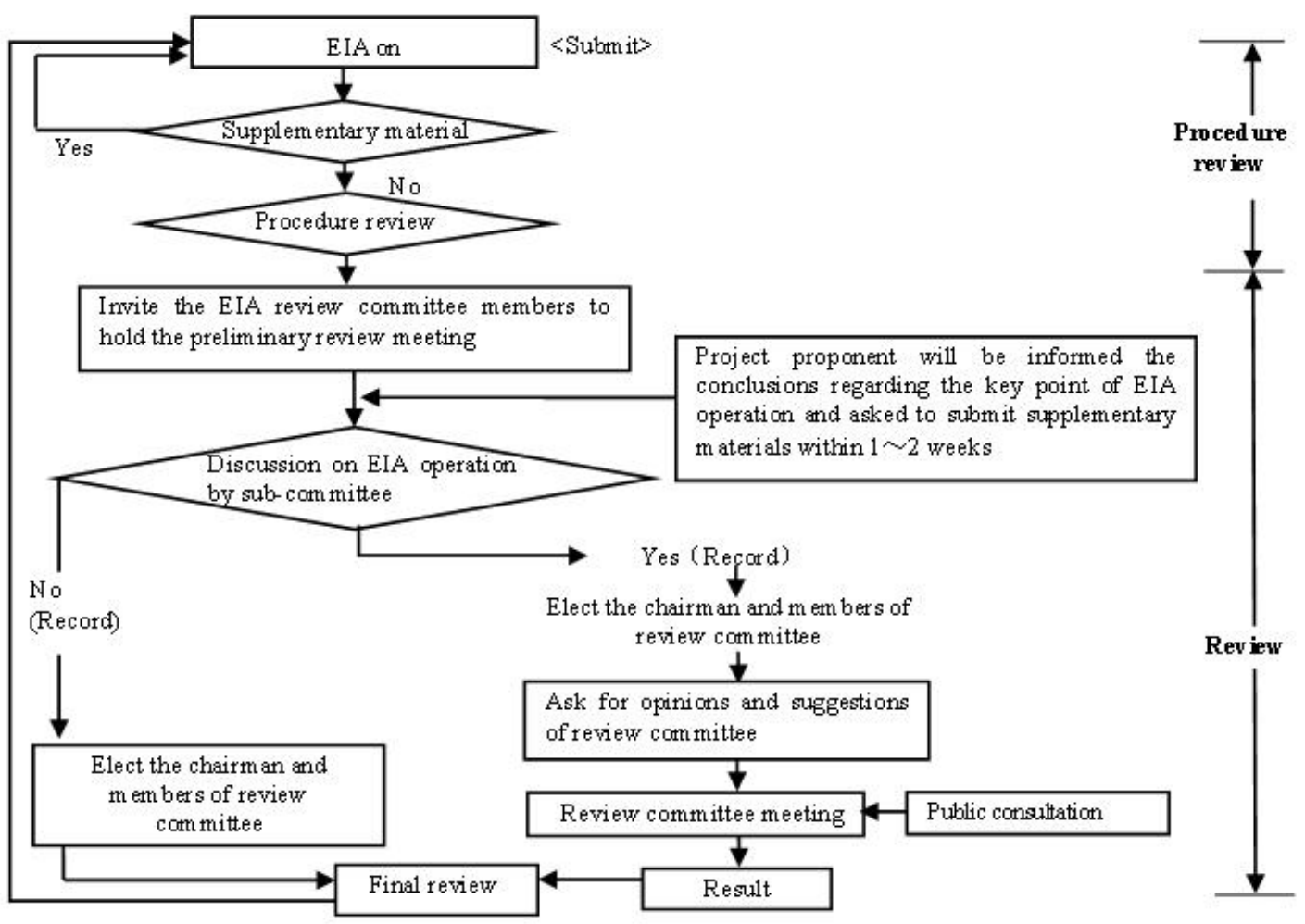

Figure 1. The EIA review process in Taiwan 

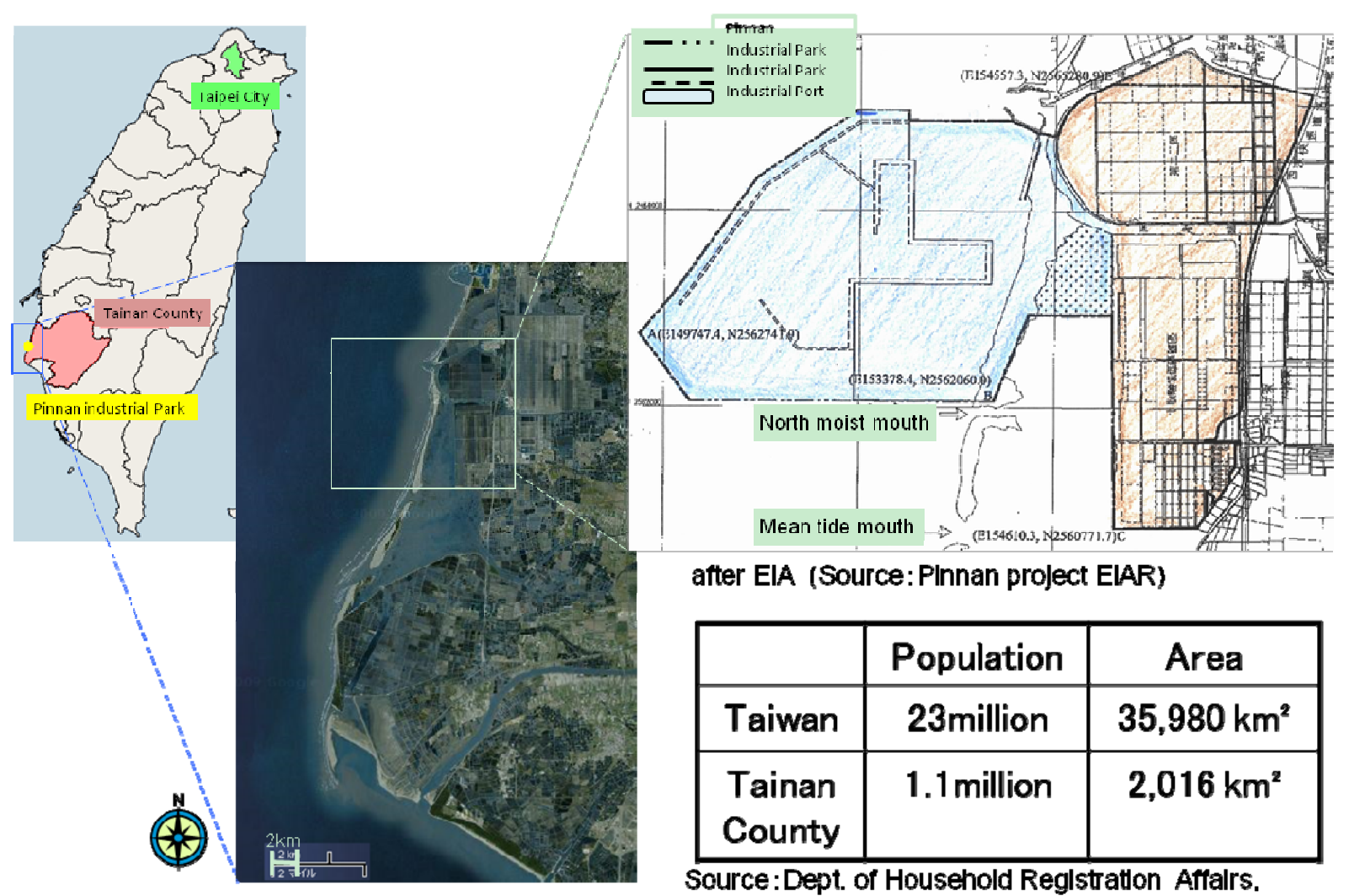

after EIA (Source: PInnan project EIAR)

\begin{tabular}{|l|c|c|}
\hline & Population & Area \\
\hline Taiwan & 23 million & $35,980 \mathrm{~km}^{2}$ \\
\hline $\begin{array}{l}\text { Tainan } \\
\text { County }\end{array}$ & 1.1 million & $2,016 \mathrm{~km}^{2}$ \\
\hline
\end{tabular}

Source:Dept. of Household Reglstratton Affalrs. MOl. Talwan 2008.12

Figure 2. Location of Pinnan industrial park 


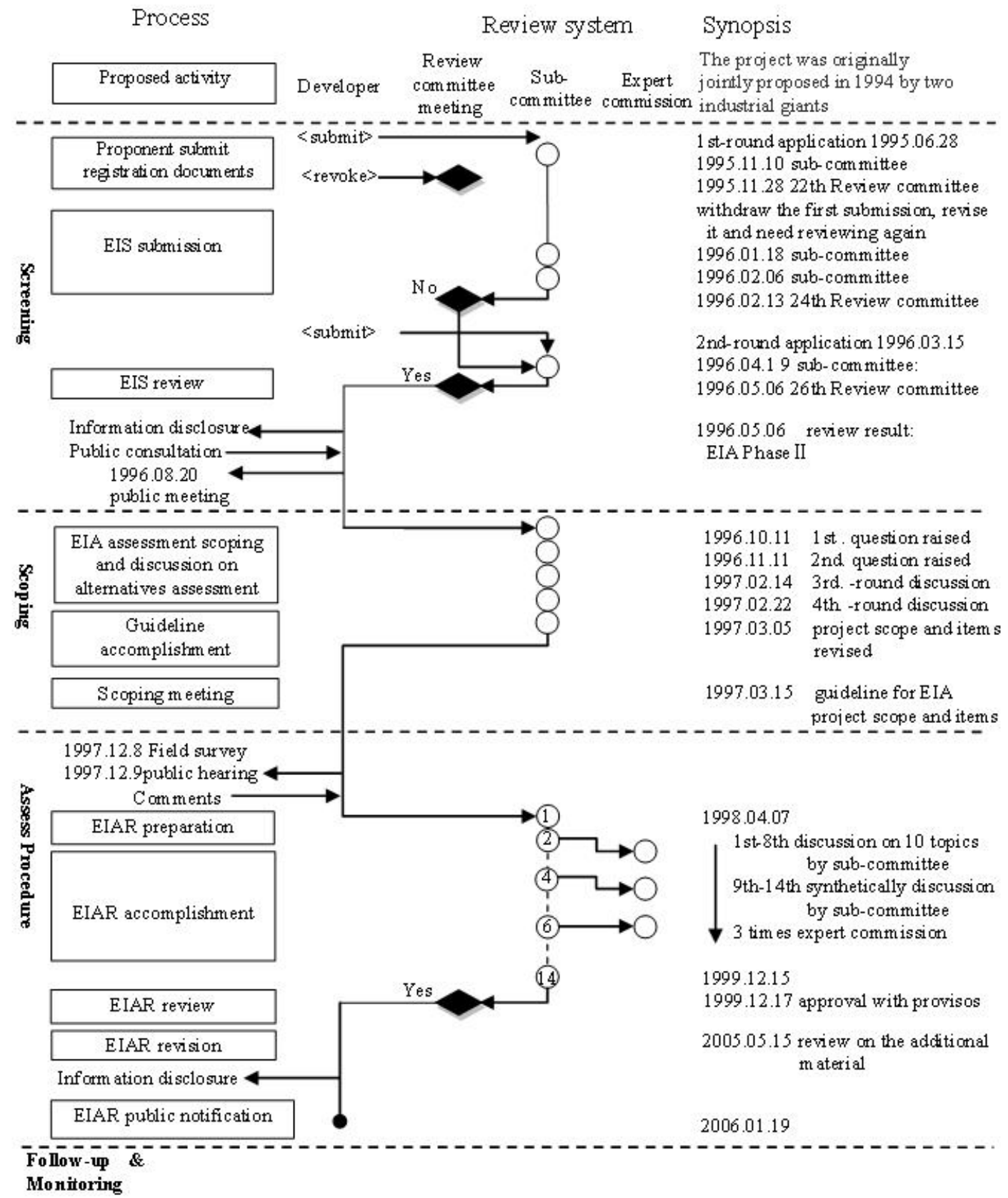

Figure 3. Review process of Pinnan industrial park EIA

Adapted from: Pinnan project EIS \& EIAR, record of proceedings 


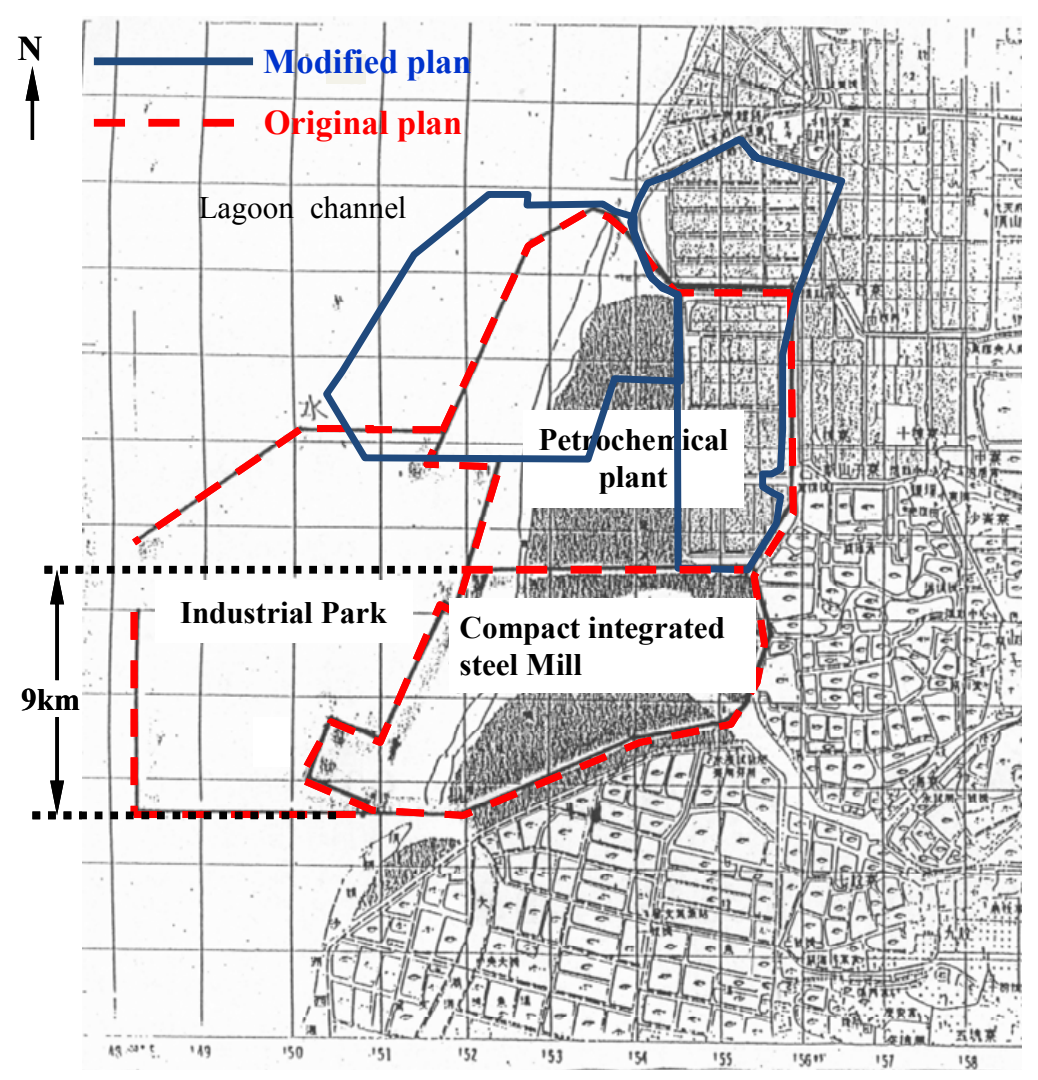

Figure 4. Original and rearranged site of Pinnan industrial park Adapted from: Pinnan project EIS \& EIAR 